AROUEOLOGÍA Y SOCIEDAD

№ 24, 2012: 393-402

ISSN: 0254-8062

RECIBIDO: MARZO DE 2012

ACEPTADO: JULIO DE 2012

\title{
EL HUANCA Y SU DIMENSIÓN SIMBÓLICA EN LA ARQUEOLOGÍA DE LA SIERRA CENTRAL
}

\author{
CARLOS FARFÁN LOBATÓN \\ UNIVERSIDAD NACIONAL FEDERICO VILLARREAL, FACULTAD DE HUMANIDADES \\ carlosf21@yahoo.com
}

\section{RESUMEN}

La arqueología siempre ha explicado la naturaleza de la cultura material dejada por antiguos habitantes de un asentamiento. A partir de ello, se ha explicado la conducta del hombre e inferido algunos significados culturales, sociales y económicos. Pero a causa de la naturaleza de los datos y, a veces, por problemas metodológicos y epistemológicos, se cae en extremos positivistas o funcionalistas. Para evitar estos extremos, pretendemos darle un enfoque basado en la interpretación de los significados simbólicos, basados en el dato arqueológico como base empírica y los datos etnográficos y etnohistóricos como datos contrastables para explicar la conducta de las sociedades. En este caso, nos referiremos a un icono poliforme denominado huanca, que por lo general es un bulto alargado de piedra y esta creado para estar parado o plantado en el suelo. Sus múltiples significados y su naturaleza, aún son vigentes en las comunidades andinas y pueden ser contrastados con el dato etnohistórico y la tradición oral, puesto que arqueológicamente es una muestra incuestionable que existió en el contexto de las poblaciones arqueológicas y áreas de cultivo, conservando su tradición y costumbre hasta la actualidad. Por ello el registro y la caracterización nos permitirán contextualizar los asentamientos arqueológicos.

Palabras Clave: Huanca, simbolismo, arqueología.

\begin{abstract}
Archaeology has always explained the nature of the material culture left by ancient inhabitants of a settlement. As it explained human behavior and inferred some meanings of cultural, social and economic. But archeology by nature of their data and at times by methodological and epistemological problems falls into extreme positivist or functionalist. To avoid these extremes, try to give an approach based on the interpretation of symbolic meanings, based on archaeological data as empirical and ethnographic and ethno historic data and testable data to explain the behavior of society's last. In this case, we refer to an icon called Polymorphic Huanca, who is usually a long lump of stone and is set to stand or planted in the ground. Their meanings and nature still exist in the Andean communities and can be contrasted with the ethno historical data and oral tradition, as archaeologically is a sample question that existed in the context of archaeological populations and crop areas, preserving their traditions and customs until now. Therefore, the registration and the characterization will allow us to contextualize the archaeological sites.
\end{abstract}

KEYwoRDS: Huanca, symbolism, archaeology. 


\section{INTRODUCCIÓN}

Los estudios arqueológicos han abarcado problemas concernientes a la cultura material, con el cual, el arqueólogo analiza e interpreta la conducta de las sociedades desaparecidas. Este análisis, por lo general, corre el riesgo de caer en el campo de la especulación, en el caso más optimista, en un resultado basado en el análisis del dato empírico orientado a un particularismo histórico subyacente. Los cuestionamientos a estas posturas han surgido a la luz de un enfoque mucho más holístico que involucra puntos de vista de la cultura, no solo como restos materiales inertes, sino como unidades domésticas, capaces de trasmitir conductas, más no solo formas y funciones. Para ello la arqueología recurre a los datos etnográficos, etnohistóricos y principalmente la tradición oral de la esfera cultural involucrada y contrasta con el dato arqueológico, de manera que el universo informativo y deductivo es mucho más amplio. En este sentido, nuestro objeto de investigación está basado en el huanca, considerado un símbolo y a la vez un icono que encierra una diversidad de significados que marcan una continuidad y vigencia dentro de las mentalidad andina. Esta vigencia se traduce en creencias y rituales de un icono que trasmite un significado polivalente, cuya existencia se remonta a periodos muy tempranos de nuestra cultura.

El huanca es un bulto de forma alargada, por lo general de piedra. Puede ser de origen natural, cuando su forma fue modelada por la naturaleza o artificial, cuando hay un tratamiento del hombre para darle esa forma alargada. Su origen se remonta a los periodos tempranos del desarrollo de la cultura andina. Aparece asociado a lo sagrado, podemos verlo en Punkuri, Chasquitambo, Caral, Chavín, etc. Su popularidad se gesta en el Horizonte Medio asociado a mitos de origen, como es el caso de los huaris. "Dicen que los huaris fueron convertidos en piedra existen siempre en el pueblo bajo esta forma. Generalmente esta piedras es llamada huanca" (Duviols 1973). Este dato es muy claro cuando se refiere a que la huanca es un huari. El huanca está relacionado a los antepasados y a la fecundidad (Op cit.). Pero ¿qué es el huari?, Tello define a los "[...] Wari como el dios de la fuerza, que según la leyenda generalizadora en casi toda la región andina, construyó por arte mágico las represas y canales de irrigación [...]" (Duviols 1973). Más adelante el autor señala que los "[...] huaris eran seres antropomorfos muy antiguos de muy elevada estatura, de much a fuerza, diestros en construir edificios y cultivar la tierra, relacionadas con el subsuelo y las aguas subterráneas. También señala que son rasgos que se desprenden de la tradición oral actual, igual como fueron arrancados de los campesinos de Cajatambo y Conchucos por los extirpadores de idolatrías[...]", (Op.cit.). Este hecho no hace más que corroborar la vigencia de una cosmovisión ligada a los mitos de origen, que explicaría la noción de un intrincado modelo racional del control del agua y la agricultura. El huanca es, pues, un símbolo y un personaje vigente que sustenta la fertilidad y la abundancia porque el huanca es también, chacrayoc y es marcayoc, es decir, es dueño de la chacra y es dueño del pueblo respectivamente. El huanca también es considerada el dueño del agua y que es el mismo huari petrificado. Dicen se "quebró una guanca grande a manera de un cuerpo amorfo y el cual mochaban y tiene tradisión que esta guanca era yndio" (Hacas, en Duviols 1986). También hay otro relato que dice: "[...] su padre le enseño una piedra larga llamada Sumac Guanca que esta junto a la cabecera de un puquio y que dicen que es dueño del dicho puquio y que primero fue yndio llamado Tupin Guailca, el cual disen y tiene tradision crio aquel puquio [...]" (Op. cit.). Estos datos explican claramente que el huanca es la litificación del ancestro, en este caso el mallqui, lo cual, evoca un tiempo mítico y un tiempo histórico como fundadores y controladores del agua. En el primer caso, el ancestro fue un indio que vivió y se mitifico al pasar el tiempo pero no se sabe cuándo. En el segundo caso, se remonta a un personaje real que por lo general es un héroe fundador de linaje o un ayllu.

Otro autor que se refiere sobre el huanca, es José Luis Gonzales (1989), donde explica cómo el huanca se puede transformar en cruz generándose un sincretismo entre la cruz y el huanca, por esta razón, en las limpia sequias o champerias aparece la cruz en el territorio del agua incluso forma parte del ritual, es una especie de dualidad y oposición que se complementan en el ritual hacia un fin, que es la propiciación y evocación del agua y subyace en contextos arqueológicos. 
En trabajo de campo nosotros hemos recogido el relato de don Benigno Hacha Mosquito, y dice:

"Allá por arriba había unos criaderos de ganado lanar, entonces cuando iba por ahí, en el lugar de Jaguajo, había los dos cerros ahí, no le dejaba pasar, y qué era, que habían dos piedras grandes y esos se habían convertido más antes en una vieja y un viejo así es que cuando la gente iba después no le dejaba pasar, tenían que ponerle su coca y su cigarro."

Este relato explica las huacas que se encuentran en la toma del canal de Jaguajo en la comunidad campesina de Huaros, ellos afirman que es el canal de runtu, (huevo) y está relacionada a los solteros. Este hecho explicaría de manera fehaciente la vigencia del huanca.

La dispersión de la presencia de huancas en los andes centrales se concentra en lo que es la sierra de Lima y al Sur del departamento de Ancash, específicamente las cuencas altas de los ríos Pativilca, Fortaleza, Ambar, Huaura, Chancay y Chillón. Este último sería el límite de las concentraciones por el Sur. Su dispersión guarda relación con un patrón simbólico muy arraigado en las sociedades del Intermedio Tardío y está basado en la adoración a sus ancestros o mallquis incorporados en mitos de origen. Sin embargo, se han hallado evidencias más tempranas de huancas asociadas principalmente a edificios sagrados o plazas por lo que su connotación tenía un significado más ligado a dioses mayores. Para el Horizonte Medio se notan escasas evidencias de estos personajes ligados a la piedra. Pero para el Intermedio Tardío, que es un periodo poswari, es de crucial importancia debido a una época de reacomodos de las sociedades que imponen un nuevo patrón de asentamiento y con ello nuevos patrones culturales basados en el concepto de la muerte, los ritos propiciatorios y la estructuración de mitos de origen y leyendas basadas en héroes fundadores que será el motivo e inspiración de su cosmovisión.

De este modo, podemos contar con el relato de Hernández Príncipe en su visita del 30 de julio de 1621 a Ocros donde, entre otras, cosas habla de Carhua Huanca un antiguo héroe fundador de los llamados Llacuaces advenedizos que vivían en Oncoy y Chilcas actuales localidades de Cajatambo y adoraban al rayo. Dice el documento que "Parana era una piedra verrugosa y muy fiera rodeada de muchos sacrificios que estaba en el asiento de Oncoy-Cancha y fungieron los dichos chilcas que era su padre antes de ir a la adoración de Carhua Guanca", (Duviols 1986). Aquí se nota claramente que Parana es antecesor de Carhua Guanca ambos eran huacas a manera de huancas de piedra, es decir al haber pasado a una dimisión de ancestro fundador de la comarca de los llacuaces. De este modo, la arqueología del huanca, es un hecho objetivo, que trasciende en el tiempo y perdura hasta la actualidad dentro de una estructura mental sincretizada.

Nuestro propósito en esta investigación es identificar los atributos y simbolismos del huanca y su continuidad en el mundo actual, así como articular las huancas arqueológicas asociadas a los asentamientos arqueológicos con las huancas que aún están en vigencia dentro de la cosmovisión y ritualidad andina funcionando como un icono cohesionador en la tradición y costumbres de los pueblos andinos.

\section{EL ESPACIO GEOGRÁFICO}

El ámbito de nuestra investigación esta limitado principalmente a la sierra de Lima y abarcan los territorios expuestos líneas arriba, es decir, las cuencas altas del Chillón, Pativilca, Fortaleza y el distrito de Huarochiri. El procedimiento implica un diagnóstico y evaluación de la dispersión de las huancas y su asociación con asentamientos prehispánicos. Los datos de campo fueron sometidos a un análisis comparativo para definir los factores diferenciales basado en las evidencias referentes a la significación de las huancas y su trascendencia en el tiempo. Los indicadores se basan en tres elementos: la asociación, el componente formal, el componente cultural, y el componente basado en lo simbólico y ritual, sustentados en discursos míticos. La asociación es quizá el elemento más determinante, debido a que 
nos ha permitido correlacionar, los distintos materiales hallados en superficie, tales como la cerámica, enterramientos con presencia de osamentas y otros elementos. El componente formal son las representaciones en piedra de los ancestros que adoptan múltiples significados en el mundo andino. El componente cultural es la filiación al que pertenece el huanca basado en el contexto y asociación. El componente simbólico está basado en los rituales de culto al agua, asociada a huacas y huancas que son los personajes míticos controladores y dueños del agua. Este último solo es factible deducir a partir del análisis de los relatos orales y documentales y principalmente de las actividades rituales en las actuales comunidades campesinas.

Los huancas casi siempre están ocupando espacios relacionados a las fuentes de agua y a las chacras. Sin embargo, hay cuatro que están relacionados a los antiguas llactas en, generalmente, los extramuros como los hallados en Pararin (Ancash) o como en Puruchuco de Huamantanga (Canta), la de Ocros (Ancash). Todos ellos se hallan en los extramuros de los asentamientos prehispánicos y están relacionados al periodo de la ocupación Inca. Su disposición cerca a los asentamientos es recurrente en cada uno de ellos, al parecer, cumplen una función calendárica de evocación y a la vez, como mallqui protector de la comarca. Este modelo impuesto por los incas estaba destinado al control político y territorial y una forma de unificar el control social a través de rituales ligados al calendario agrario que debían cumplir todos los pueblos conquistados ${ }^{1}$. Por esta razón, las plazas sagradas en los extramuros son un agregado posterior impuesto por los incas, es clara la evidencia arqueológica en este caso. Estas plazas, por lo general, están dotados de un huanca en la parte central y se convirtió en un elemento integrador.

La presencia de huancas en el ámbito de la sierra central nos ha permitido establecer un registro sistemático de las evidencias, con el fin de encontrar recurrencias y variabilidad en los componentes formales y de significación, de este modo, relacionar a un asentamiento prehispánico y cómo aun su vigencia es percibida hasta la actualidad en las festividades de propiciación del agua. Para un mejor registro hemos empleado fichas analíticas que permitieron ordenar la información y que, a la vez, generar otra ficha de inventario de cada huanca identificada con información basada en los elementos visibles en superficie y sus relaciones con pueblos actuales. Toda esta información está referida a la presencia o ausencia de los elementos huanca y su contexto sociocultural en el tiempo, su vigencia y trascendencia en las comunidades actuales y de este modo articular una metodología interpretativa amplia.

Al mismo tiempo, se ha manejado dos tipos de documentación: una, basada en datos obtenidos de las bibliotecas que conforman el antecedente de la investigación, documentos o manuscritos (visión etnohistórica). La otra, está basado en el corpus y protocolo de datos obtenidos en el campo, producto de las prospecciones. Estas informaciones fueron procesadas desde una visión arqueológica tomando como criterio la evaluación critica. Para este tópico, se cuentan con un cumulo de informaciones documentales basadas en relatos y testimonios originales del siglo XVI y XVII. Así como documentos recientes de carácter interpretativo de los huancas.

\section{Atributos Del HUANCA}

Por su naturaleza polimórfica el huanca adopta múltiples atributos que pueden ser diferenciados gracias a que su vigencia en la actuales comunidades andinas cobran vigor e identidad, aunque en muchos casos se está perdiendo o simplemente se ejecuta como un vago acto evocativo practicado casi por los más ancianos o adultos, no tanto así para la juventud que prácticamente ya perdió esas costumbres. En este sentido nuestra labor ha sido recuperar, a través del relato oral y la observación participante, todos los detalles y rasgos de las manifestaciones culturales referentes al ciclo agrario, ciclo ritual y principalmente la identificación de lugares sagrados o míticos.

1 Para ampliar este concepto véase el artículo "La bipartición del espacio y las plazas sagradas en los asentamientos prehispánicos de la cuenca del Chillon" 
A continuación presentamos el Cuadro I, donde se resume los tributos del huanca que claramente tiene una larga connotación polivalente dentro de la mentalidad andina que grafica su cosmovisión.

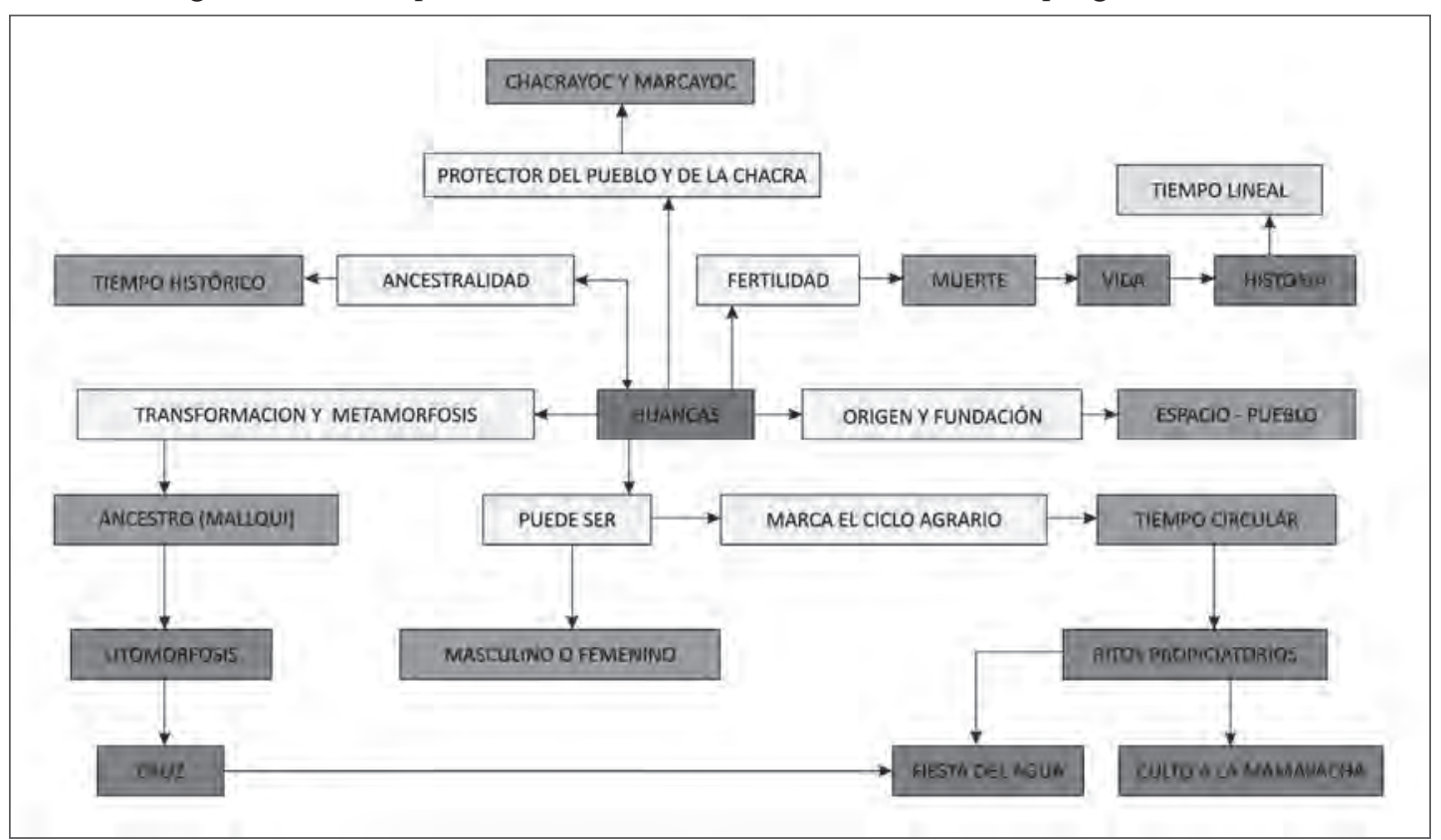

Cuadro I. Esquema de Atributos del Huanca

La Fig. 1 muestra, de manera esquemática, la tripartición vertical. Es un concepto muy arraigado en la cosmovisión andina, debido a que articula tres espacios, que en este caso, el huanca es el eje controlador que se proyecta en la vida cotidiana. La esencia fundamental radica en que el huanca por su naturaleza polivalente se comporta de distintas maneras. Al estar plantado en tierra se conecta con la mamapacha y el mundo en que vivimos, este hecho, lo convierte en un símbolo fertilizador, dado que el huanca es un ancestro litificado y puede controlar el agua que discurre por los canales. Dentro de esta estructura, tanto la serpiente como el cóndor actúan como intermediarios entre el Ucupacha y el Kaypacha, es decir entre el mundo de los muertos y el mundo de los vivos o entre el Hanapacha y el Kaypacha para el caso del cóndor. Sin embargo, el huanca está relacionado al pueblo o marca, puesto que cuando actúa de ancestro se evoca a un tiempo de fundación, de origen. Esto es factible identificar en los discursos míticos relacionados al agua, en la llamada fiesta del agua. Arqueológicamente es factible identificar en las tumbas o espacios sepulcrales de la pareja mítica que se hallaron en Cantamarca, Aynas, Huishco y Tauripunku. Estos entierros son muy recurrentes en áreas expresamente remarcadas en la población como espacios sepulcrales dedicados a estos ancestros. El mismo fenómeno es factible identificar en los sepulcros de los machays o cuevas donde se enterraron los personajes más importantes con su parentela acompañada y quizá en rituales y ofrendas de sacrificios humanos.

En la Fig. 2 observamos que la huanca también es la momia o ancestro, también llamado mallqui. Estos mallquis, míticamente se convierten héroes guerreros, que acompañan en las avanzadas guerreras y se convierten en conquistadores o fundadores. Aquí es importante señalar una cita: “[...] Carhuahanca, Llacsahuanca, Carihuanca, Huarachuanca fueron indios conquistadores, estaban arriba del pueblo de Carhuapampa. Estos indios fueron llacuaces que vinieron del Titicaca los cuales trajeron piedras huancas", (Duviols 1986: 59). Aquí es claro la alusión al huanca, puesto que se refiere al fundador, cuyo origen es altiplánico y se refiere también a su ascendencia llacuaz. Hay innumerable mitos respecto a los llamados llacuaces que son advenedizos y son adoradores del rayo (Arriaga 1920). La Momia 
también está inmersa dentro de un tiempo histórico, puesto que se refiere a un héroe o ancestro que vivió en una época, quizá de fundación, constructor de canales. Pero el tiempo mítico está basado en el discurso mítico que envuelve un contexto espacial que articula el pueblo viejo y el pueblo actual. Este tiempo se evoca en los rituales del agua.

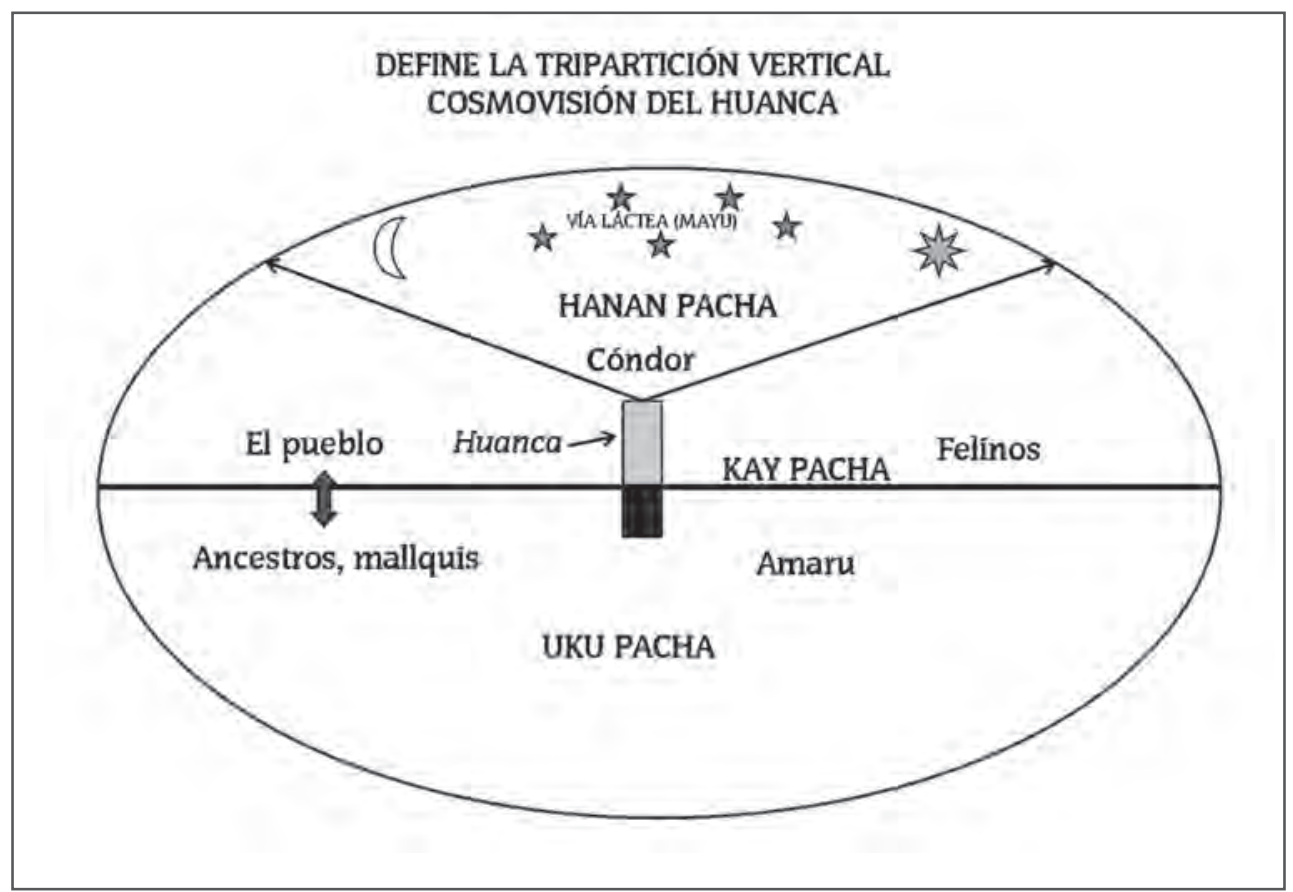

Figura 1. Esquema de la tripartición del espacio. Diseño Carlos Farfán.

\section{ESTRUCTURA DUAL}

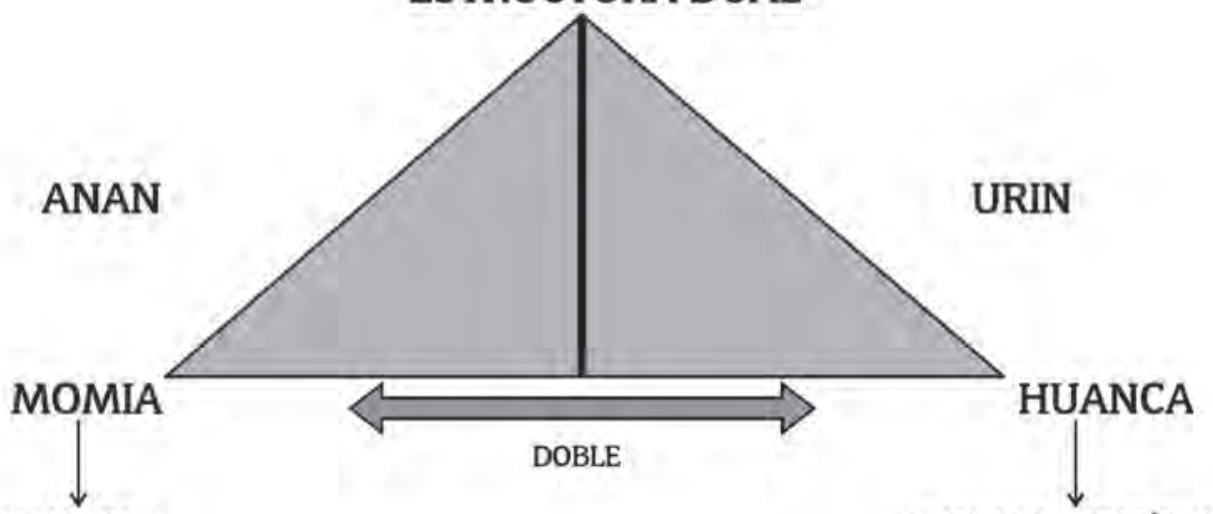

SON MALLQUIS

MARCA LA POSICIÓN DEL SOL

ANCESTROS SOLSTICIOS Y EQUINOCCIOS

HÉROES GUERREROS

FUNDADORES

CALENDARIO SOLAR

TIEMPO HISTÓRICO

CALENDARIO AGRARIO

TIEMPO MFTICO

MARCA EL TIEMPO CIRCULAR

Figura 2. Estructura dual del Huanca. Diseño Carlos Farfán. 


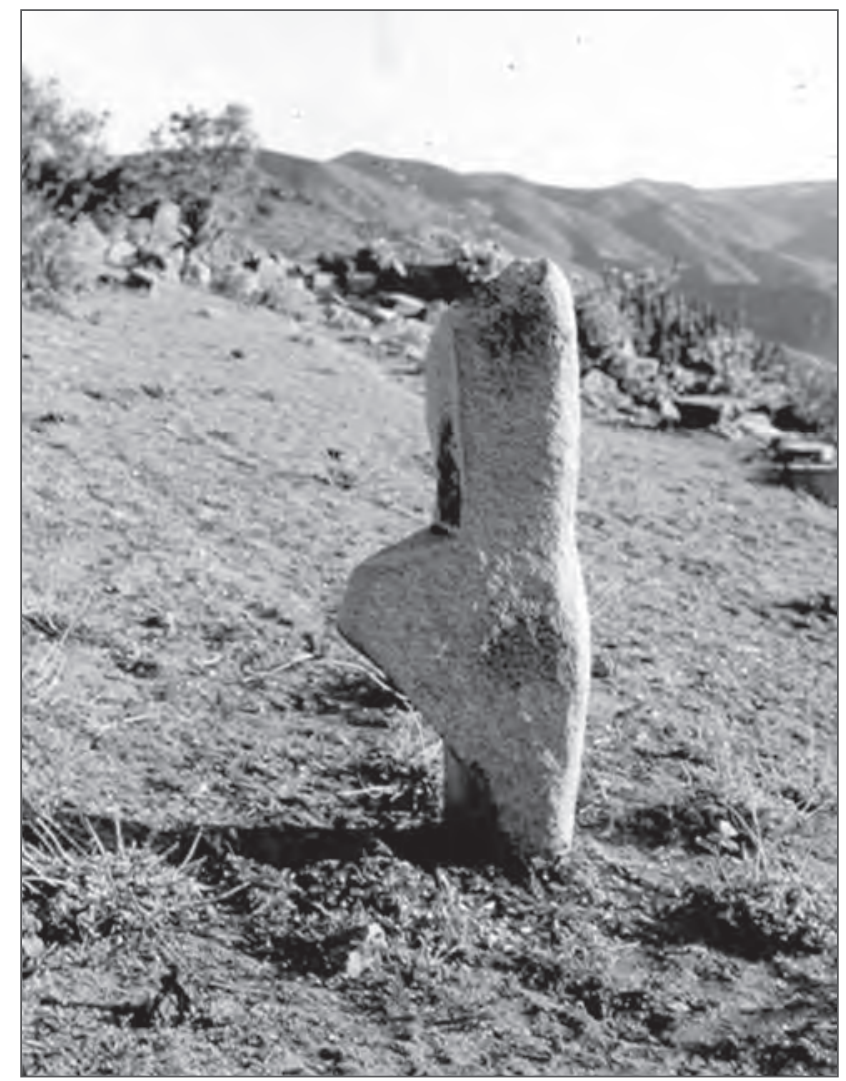

Figura 3. Huanca en Huancapata de Puruchuco, Huamantanga. Foto Carlos Farfán.

\section{RITOS PROPICIATORIOS LIGADOS A LA AGRICULTURA}

La agricultura es un indicador del desarrollo económico de las sociedades prehispánicas. Por ser uno de los motores de su desarrollo están ligados a una estructura de ritualidad y simbología, por lo que todo acto dentro del ciclo agrario está fijado por un calendario ritual y un calendario agrario, de modo que aparece un poder ligado a la ritualidad y lo sagrado y otro ligado a la producción y control de las fuerzas productivas. De este modo, podemos decir que el poder económico en las sociedades prehispánicas, al menos, de la cuenca del Chillón ha estado centrado en el control de los sistemas hidráulicos y la agricultura, que conllevan al manejo racional del espacio, consecuentemente del agua. Esta relación espacio-agua incorporado a la dimensión simbólica, nos permite entender otra relación sociedad -ritual. Ambas relaciones están imbricadas en el manejo y control del agua y la agricultura.

No es casual que en la mayoría de los asentamientos actuales de la cuenca alta del Chillón, Chancay, Lurín, se practiquen aun ritos propiciatorios y fiestas dedicadas al agua. Si bien es cierto que estos rituales consistentes en la memoria de los pueblos obedece a sociedades con escaso recurso de agua o sociedades propensas a sequias cíclicas, los actos propiciatorios son un argumento de justificación cuyas plegarias deben ser escuchados por los dioses del agua y de la tierra. En este sentido, estos pueblos como Huaros, Huacos, Culluhuay, San Miguel, San Buenaventura, San José, Lachaqui y Arahuay, solo de la cuenca del Chillón, son ejemplos de esta permanencia muy arraigada de evocar los mitos de origen de las aguas y sus pueblos. Al parecer en este límite se consagra los valores de reciprocidad e intercambio, de la instauración del orden y principalmente la racionalidad y manejo del agua y los recursos que los incas supieron integrar y conciliar en los pueblos conquistados. 
El control simbólico de las aguas cargadas de rituales y mitos de origen, explican con claridad la circulación del agua dentro de un calendario agrario ligado a la cosmovisión altamente sofisticada (Farfán 2002). De este modo, las evidencias materiales de estos actos aparecen en los cauces de los canales, como son las huancas, plazas sagradas y un sinnúmero de espacios denominadas "paradas" que es una especie de espacio ritual, a lo largo del cauce del canal y las chacras. Aquí se evocan los mitos de los héroes civilizadores, constructores de canales, mallquis litificados, etc. Estos parajes de ancestros con estos atributos son la sustentación material de estos actos que según la narración oral pertenecería a épocas pretéritas, es decir a la época prehispánica. Partiendo de este principio, asociamos a los sitios arqueológicos y su entorno y se explicaría la continuidad cultural de estos pueblos. Sin embargo la ritualidad y los mitos de origen, son dos factores vigentes todavía en los pueblos actuales de la sierra de Lima, que están ligados al agua a la ancestralidad y consecuentemente a la muerte. En muchos casos las terrazas de cultivo son la morada de los ancestros, como en el caso de las terrazas de Huracaure y Aynas en Huaros (Canta). Si a esto le agregamos la presencia de huancas los denominados chacrayoc o dueños de la chacra estaríamos hablando de una estructura simbólica muy compleja que no solo denota un factor propiciatorio dentro del discurso mítico o ritual, sino otro factor ordenador donde se involucra lo social lo económico y político. De ahí que tanto el rito como el mito se convierten en medios de control ideológico capaces de articular el funcionamiento económico y social de estos pueblos.

\section{Discusión}

La sierra central y principalmente las cabeceras de las cuencas del Huaura, Chancay, Chillón, Rímac y Lurín conforman una esfera cultural con rasgos culturales comunes. Por lo general, arqueológicamente hablando, no hay una alta concentración de asentamientos para los periodos tardíos en estas zonas, quizá por lo agreste y accidentada geomorfología. También por el patrón de asentamiento de estas sociedades que eligieron territorios planos, lechos de antiguos cauces del rio, terrazas aluviales,

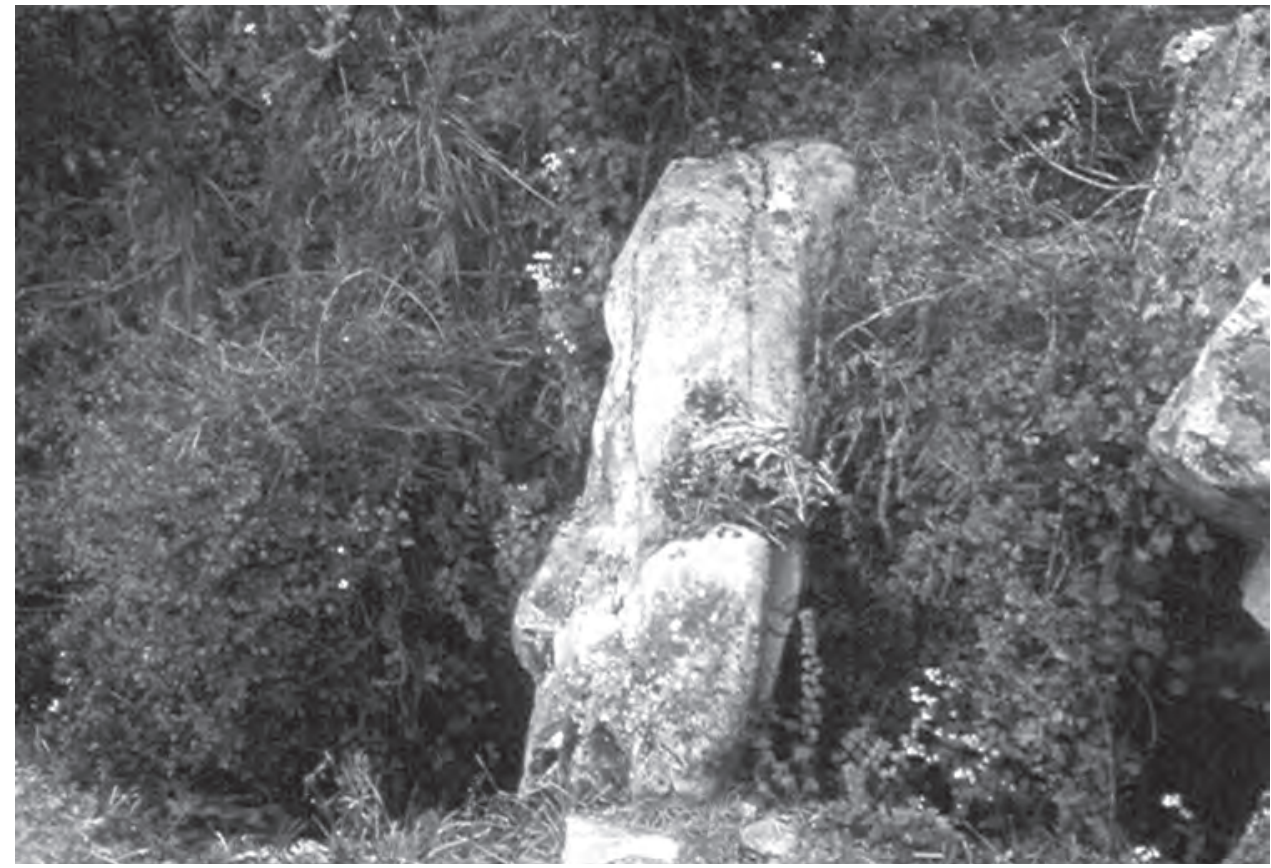

Figura 4. Huanca en la toma del canal de Runtu, Huaros, Canta, Foto Carlos Farfán. 
etc. Sin embargo, en periodos tardíos después del siglo X d.C., el patrón de asentamiento se complica y los pueblos eligen de manera casi homogénea vivir en las cumbres de los cerros, casi alejado de los recursos hídricos y un sobre esfuerzo para construir sus equipamientos habitacionales y productivas. Es aquí donde surge un cambio drástico en la cosmovisión y conceptos sobre la muerte y lo sagrado que está relacionado a la propiciación del agua, a la fertilidad, quizá debido a que existió un dramático cambio en el clima con sequias donde la escasez del agua era perceptible, por lo que se configuro una estructura ritual y aparecieron los mitos de origen ligados a ancestros fundadores, mallquis, héroes civilizadores que explicaban los orígenes. Es aquí donde encontramos el huanca un personaje convertido en piedra (Duviols 1973) con el fin de perennizar su imagen y poder pero a la vez equilibrar la vida cotidiana e instaurar el orden. Quizá este autor es el más entendido en este tipo de elementos sagrados, debido al dominio de documentos relacionados a Cajatambo. Los territorios con mayor presencia de huancas son sin duda, la sierra de Cajatambo y el sur de Ancash y trasciende hasta Huarochiri. Tanto en el manuscrito quechua de Huarochiri (Taylor 1986), como en Hechicerías de Cajatambo, (Duviols 1986), se menciona en forma reiterada la presencia de huancas relacionadas a las chacras y principalmente al agua. Nosotros hemos explorado la zona de Ocros siguiendo los relatos de la visita de Hernández Príncipe (Duviols 1986). Aquí identificamos varias huancas que están dispersas en las chacras, lo que corrobora lo dicho en los documentos. Aún no sabemos en qué contexto subsisten ni como se explica su presencia. A diferencia de los Huancas del Chillón alto que si están contextuados a canales, como las de Mirpo y Runtu en Huaros, a diferencia de Ocros que están relacionadas a las chacras. En este sentido, los estudios aún no están concluidos recién estamos tratando de explicar arqueológicamente.

\section{BIBLIOGRAFÍA}

ARRIAGA, J.

1920 [1621] “Extirpación de Idolatrías del Perú". En: Colección de Libros y Documentos Referentes a la Historia del Perú, Tomo I (Segunda Serie), 215 p. Lima.

CLAVERIAS, R.; A. VILLEGAS; B. SALAS y P. S. AGUILAR

1986 “Sistemas de Riego y estrategias productivas en las economías campesinas andinas" En: Allpanchis, $N^{\circ} 27$, Año XVIII, Cusco: Instituto de Pastoral Andina.

DILLEHAY, Tom

1976 Competition and cooperation in a prehispanic multi-ethnic system in the Cetral Andes. Ph.D en Antropología. Austin: Universidad de Texas.

1987 "Estrategias Políticas y económicas de las etnias locales del valle del Chillón durante el periodo prehispánico". En: Revista Andina 2: 407-456, Año V, Cusco: Centro Bartolomé de las Casas.

DUVIOLS, Pierre

1973 "Huari Llacuaz: Agricultores y pastores. Un dualismo prehispánico de oposición y complementaridad". En: Revista del Museo Nacional, Tomo XXIX, Lima Perú.

1979 "Un simbolismo de la ocupación, emplazamiento y explotación del espacio. El monolito huanca y su función en los andes prehispánicos”. En: L'HOMME, Revue Francaise d'antrtropologie. Tome XIX, Avril-Juin 1979. Número 2.

1986 Cultura Andina y Represión: Procesos y visitas de idolatrías y hechicerías, Cajatambo, siglo XVII. Cusco: Centro de Estudios Rurales Andinos Bartolomé de las Casas.

FARFÁN LOBATÓN, Carlos

1995 “Asentamientos prehispánicos en la cuenca alta del Chillón”. Gaceta Arqueológica Andina 24: 31-61, Lima: INDEA.

2000 "La Ocupación Inca en Cantamarca". En: Arqueología y Sociedad N 3: 173-198. Lima: Museo de Antropología y Arqueología, UNMSM.

2002 "Simbolismo en torno al agua en la comunidad de Huaros, Canta". En: Boletín del Instituto Francés de estudios Andinos, $\mathrm{N}^{\circ} 31$ (1): 115 - 142, Lima. 
GOLTE, Jürgen

1980 La racionalidad de la organización andina. Lima: IEP.

GONZÁLES, José Luis

1989 El Huanca y la Cruz: Creatividad y autonomía en la religión popular. Lima: Ediciones IDEA y TAREA.

GUELLES, Paul

1986 "Sociedades Hidráulicas en los andes" En: Allpanchis, N 27, Año XVIII, Cusco: Instituto de Pastoral Andina.

PAREDES, Ponciano

2003 "Ocros: 500 años después: Acerca de los linajes de Caque Poma y Tanta Carhua." En: Boletin de la Sociedad Geográfica de Lima, Año 112, Vol. N¹16.

ROSTWOROWSKI DE DIEZ CANSECO, María

1977 Señoríos de Lima y Canta. Lima: IEP.

1978 Etnia y Sociedad. Costa Peruana Prehispánica. Lima: IEP.

1986 Estructuras Andinas del Poder: ideología religiosa y política. Segunda edición. Lima: IEP.

VALDERRAMA, R. y C. ESCALANTE

1988 Del Tata Mallky a la Mamampacha. Riego, Sociedad y Ritos en los Andes Peruanos. 243 p. Lima: DESCO. Centro de Estudios y Promoción del Desarrollo. 